\title{
PROPUESTA PARA LA REGIONALIZACIÓN PLURIDEPARTAMENTAL DEL PERÚ
}

\author{
Nissim Alcabés \\ Universidad ESAN \\ nalcabes@esan.edu.pe
}

\section{Resumen}

Este artículo plantea la transición de las actuales regiones-departamento a regiones pluridepartamentales. Discute la conveniencia de una región piloto y presenta algunos criterios para formar las regiones pluridepartamentales y determinar la ubicación de las capitales regionales. También formula planteamientos para la elección de diputados y la constitución de la Cámara de Senadores, así como para la formación de los gobiernos subregionales. Finalmente, presenta una propuesta de agrupaciones departamentales para constituir ocho regiones y cita una alternativa de regionalización por cuencas.

Palabras clave: regionalización, normas constitucionales, organización política, gobiernos regionales, gobiernos subregionales.

\begin{abstract}
This paper discusses the transition from the present single-department regions to a structure of multiple-department regions. It discusses the convenience of creating a pilot region and provides some criteria to create multi-department regions and choose the location of the regional capitals. It also provides guidelines to elect representatives to the Chamber of Deputies and the creation of a Senate. Finally, it outlines eight regions to be created by grouping several departments, and an alternative proposal to create regions based on river drainage basins.
\end{abstract}

Key words: regionalization, constitutional provisions, regional governments, sub-regional governments. 


\section{Antecedentes}

En el Perú, la descentralización ha sido un anhelo nacional desde los inicios de la República. La Constitución de 1828 estableció las Juntas Departamentales, que subsistieron hasta 1834 . De 1874 a 1880 existieron los Consejos Departamentales, intento interrumpido por la Guerra del Pacífico. Ya en el siglo XX, la Constitución de 1933 normó los Consejos Departamentales en su Título X: Administración Departamental y Municipal, los cuales no llegaron a constituirse.

La Constitución de 1979 (en el Capítulo XII: De la descentralización, gobiernos locales y regionales, parte del Título IV: De la Estructura del Estado) estableció en su artículo 259: «Las regiones se constituyen sobre la base de áreas contiguas integradas histórica, económica, administrativa y culturalmente. Conforman unidades geoeconómicas.». La novena disposición final y transitoria establecía las normas para llevar adelante la regionalización. De acuerdo con ellas se aprobó la Ley de Bases de la Regionalización (Ley 24650), del 20 de marzo de 1987, y subsecuentemente once leyes orgánicas de creación de las diversas regiones. Aquellas regiones que llegaron a establecerse cesaron a partir del golpe del 5 de abril de 1992.

La Constitución de 1993 señala en su artículo 190: «Las Regiones se constituyen por iniciativa y mandato de las poblaciones pertenecientes a uno o más departamentos colindantes. Las provincias y los distritos contiguos pueden asimismo integrarse o cambiar de circunscripción. En ambos casos procede el referéndum, conforme a ley.». En sus disposiciones finales y transitorias duodécima y décimo tercera la Constitución estableció la «organización departamental política de la República» que correspondía a los 25 departamentos existentes y además señalaba: «... mientras se constituyen las Regiones y hasta que se elija a sus presidentes [...] el Poder Ejecutivo determina la jurisdicción de los Consejos Transitorios de Administración Regional [ya entonces en funciones] según el área de cada uno de los departamentos establecidos en el país.».

La Ley de Reforma Constitucional (Ley 27680), del 6 de marzo de 2002, estableció el nuevo texto del Capítulo XIV del Título IV de la Constitución de 1993. Así, el artículo 190 dispone: «Las regiones se crean sobre la base de áreas contiguas integradas histórica, cultural, administrativa y económicamente, conformando unidades geoeconómicas sostenibles. / El proceso de regionalización se inicia eligiendo gobiernos en los actuales departamentos y la Provincia Constitucional del Callao. Estos gobiernos son gobiernos regionales.».

\section{La transición de los departamentos-regiones a las regiones pluridepartamentales}

Sin duda fue un error constituir en regiones a los departamentos existentes pues, por una parte, simplemente se cambió de nombre a una unidad jurisdiccional $\mathrm{y}$, por otra, la situación creada dificulta el tránsito a verdaderas regiones pluridepartamentales debido a que existen ahora 25 presidentes regionales y decenas de consejeros regionales, de los cuales muchos pueden ver desaparecer sus posibilidades de mantener sus actuales posiciones con el cambio. Sin embargo, la situación existe y la pregunta que se plantea es: ¿cómo lograr que las poblaciones adopten un esquema de regiones pluridepartamentales? 
Perú: extensión, población y provincias dẹ los departamentos-regiones

\begin{tabular}{|c|c|c|c|c|}
\hline & $\begin{array}{l}\text { Kilómetros } \\
\text { cuadrados* }\end{array}$ & Población* & $\begin{array}{l}\text { Población** } \\
\text { (miles) }\end{array}$ & Provincias* \\
\hline NORTE & 188777,37 & 7183916 & 7805 & 66 \\
\hline Tumbes & 4669,20 & 193840 & 216 & 3 \\
\hline Piura & 35892,49 & 1545771 & 1711 & 8 \\
\hline Lambayeque & 14231,30 & 1093051 & 1151 & 3 \\
\hline La Libertad & 25499,90 & 1465970 & 1573 & 12 \\
\hline Cajamarca & 33317,54 & 1411942 & 1550 & 13 \\
\hline Amazonas & 39249,13 & 406060 & 450 & 7 \\
\hline Áncash & 35914,81 & 1067282 & 1154 & 20 \\
\hline CENTRO & 117693,97 & 3295507 & 3607 & 35 \\
\hline Ica & 21327,83 & 649332 & 721 & 5 \\
\hline Huánuco & 26848,85 & 776727 & 845 & 11 \\
\hline Pasco & 25319,59 & 247872 & 284 & 3 \\
\hline Junín & 44197,23 & 1190488 & 1289 & 9 \\
\hline Huancavelica & 22131,47 & 431088 & 466 & 7 \\
\hline LIMA & 34948,57 & 8270532 & 8968 & 2 \\
\hline Callao & 146,98 & 773701 & 824 & 1 \\
\hline Lima & 34801,59 & 7496831 & 8144 & 10 \\
\hline SUR & 302851,34 & 4808434 & 5258 & 59 \\
\hline Arequipa & 63345,39 & 1072958 & 1139 & 8 \\
\hline Moquegua & 15733,97 & 147374 & 167 & 3 \\
\hline Ayacucho & 42814,80 & 527080 & 582 & 11 \\
\hline Tacna & 16075,89 & 277388 & 318 & 4 \\
\hline Apurímac & 20895,79 & 426094 & 486 & 7 \\
\hline Puno & 71999,00 & 1199398 & 1314 & 13 \\
\hline Cusco & 71986,50 & 1158142 & 1252 & 13 \\
\hline ORIENTE & 556563,04 & 1389264 & 2309 & 13 \\
\hline Loreto & 368851,95 & 880471 & 944 & 6 \\
\hline Ucayali & 102410,55 & 424410 & 469 & 4 \\
\hline Madre de Dios & 85300,54 & 84383 & 108 & 3 \\
\hline PERÚ & 1285215,60 & 25661690 & 27947 & 184 \\
\hline
\end{tabular}

* Gran Atlas Universal. Vol. 3. Lima: Editorial Sol 90 / El Comercio. Cifras de población estimadas al año 2000.

** Informe sobre Desarrollo Humano. Perú. Cuadro 2.6. Lima: PNUD. Cifras al año 2006, expresadas en miles.

Resulta altamente deseable que el proceso sea impulsado directamente por la población a través de sus diversas agrupaciones -colegios profesionales, asociaciones empresariales, asociaciones laborales, instituciones culturales y sociales y universidades, entre otras- que presenten y analicen distintas propuestas, de modo que al perfeccionarse estas se pudiese llegar a una o dos alternativas que se someterían al proceso de referéndum. ¿Cuánto tiempo puede tomar este proceso? Dependerá del interés que manifiesten las poblaciones por definir sus preferencias. Para despertar tal interés se debe dar intensa difusión al proceso y a los planteamientos alternativos existentes. Los medios de comunicación desempeñarán un importante papel en este sentido. 
La alternativa sería que se dictase una ley (¿de nivel constitucional?) que estableciera regiones pluridepartamentales con base en las preferencias de la población expresadas de manera informal o elaboradas a partir de estudios realizados por organismos especializados. Los pobladores de distritos y provincias colindantes con otra región deberían poder manifestar en un referéndum su preferencia para incorporarse a ella.

\section{1. ¿Una región piloto?}

Hay quienes abogan por el establecimiento de una región piloto que permita «experimentar» la consolidación de dos o más departamentos. Sin duda, esta propuesta es atractiva pues crea la ilusión de que se podrá aprender de la experiencia. ¿Será realmente así? Para determinarlo se debe tener en cuenta los siguientes factores:

- Las diversas zonas de nuestro país son muy distintas en aspectos históricos, culturales, lingüísticos, étnicos, aspectos que solo son modificables en el largo plazo. Asimismo, se aprecia una notable diferencia en el tamaño de la población de los departamentos del norte y el sur del país.

- Estamos frente a la realidad de que la transferencia de «competencias» no ha avanzado suficientemente pese al tiempo transcurrido. Este es un hecho que se debe tomar en consideración y que señala la importancia de avanzar en las tareas previas al traslado de competencias.

- El éxito o el fracaso de una región piloto dependerá en gran medida de las habilidades de dirección y administración de sus responsables. No es posible suponer a priori la existencia de situaciones similares en otras áreas del país. Habrá variaciones, quizá importantes.

- La creación de una región piloto determinará que el gobierno nacional (o central) deba mantener simultáneamente la relación con la región pluridepartamental piloto y con las demás regiones-departamento, ambas con distintos requerimientos. ¿Podrá nuestra administración pública hacer frente con éxito a tal situación?

Soy partidario de la regionalización pluridepartamental simultánea en todo el país, lo que requiere de un minucioso planteamiento previo a cualquier acción legal; la revisión, y quizá la simplificación, de la normatividad; la capacitación adecuada de los cuadros administrativos en todos los niveles - pues de ellos depende parte importante de la buena marcha de las administraciones regionales- $\mathrm{y}$ una intensa difusión de las nuevas normas y de las fallas observadas hasta hoy en el proceso de regionalización.

\subsection{Algunos criterios para establecer las regiones pluridepartamentales}

Además de la contigüidad territorial de los departamentos concernidos y de los factores históricos, étnicos, culturales y otros que son requisitos constitucionales, pueden considerarse los siguientes:

- La nueva región debe integrar tres o más departamentos de dos o tres regiones naturales (costa, sierra y selva).

- La existencia o la posibilidad de construir vías de comunicación entre los departamentos y los puertos en el océano Pacífico o en conexión con las vías interoceánicas. 
- La existencia de vías de comunicación usadas en la actualidad para el tránsito de un departamento a otro (por ejemplo, de Cusco a Madre de Dios).

- Una razonable dotación de recursos naturales que permitan el desarrollo sostenible.

- La probabilidad de persuadir a la población de aceptar las propuestas de agrupación.

- La identificación de distritos o provincias que podrían preferir incorporarse a determinada región colindante.

- La región deberá contar con dos o tres polos de desarrollo ya existentes como base inicial de su futuro desarrollo.

- En la sierra y la selva influirá el acceso a ríos navegables.

\subsection{Sede del gobierno regional}

La sede del gobierno regional NO debe ser alguna de las capitales de los departamentos que la integran. La capital deberá ser una población ubicada en el centro de la región. Podrá ser una capital de provincia o de distrito que cuente con adecuadas vías de comunicación con el resto de la región. Esto posiblemente signifique inversiones para la construcción de las instalaciones necesarias. Se eliminaría así un factor de rivalidad entre los diversos departamentos.

\section{Algunos planteamientos de organización política}

\subsection{Normas constitucionales}

La creación de las regiones llevaría a la necesidad de modificaciones importantes en las normas constitucionales para asegurar una adecuada representación política de la población. Así, por ejemplo:

- La elección de diputados que representen a la población se efectuaría por distritos electorales con aproximadamente igual número de electores, digamos 133 000. (En las últimas elecciones hubo aproximadamente $16000000 \mathrm{de}$ electores inscritos para elegir a 120 congresistas, lo que da el promedio de 133000.)

Estos distritos electorales no tendrían necesariamente los límites de las provincias existentes. Cada distrito electoral elegiría un diputado, señalando los votantes su primera y segunda preferencia dentro de la lista de candidatos inscritos, si se adoptara el sistema de segunda vuelta. Este planteamiento demandaría el estudio de experiencias semejantes y la revisión de las normas electorales.

- La bicameralidad sería necesaria. La Cámara de Senadores estaría integrada por cinco senadores elegidos por cada región. Si fueran ocho las regiones, el Senado tendría 40 miembros. Los electores señalarían su preferencia por cinco candidatos para primera opción y cinco para segunda opción.

Esto permitiría que los pobladores de los departamentos que integraran la región tuviesen opción de elegir a candidatos de su mismo departamento (no se anticipa regiones que agrupen más de cinco departamentos). Resultarían electos los candidatos que hubiesen obtenido las cinco primeras mayorías. Cabe esperar que tales candidatos procedan de distintos departamentos. 


\subsection{El gobierno regional y los gobiernos subregionales}

Además del gobierno regional se tendrían consejos departamentales, concejos provinciales y concejos distritales.

El gobierno regional estaría integrado por un gobernador y un vicegobernador regional elegidos directamente por la población (no es aconsejable la denominación de «presidente») y por un consejo regional integrado por los alcaldes departamentales, los alcaldes provinciales (si fueran menos de cinco; si fueran más, rotarían en el cargo). También, cinco ciudadanos residentes en los distintos departamentos de la región elegidos por voto popular directo.

El consejo departamental tendría un alcalde y un teniente alcalde departamental elegidos directamente por la población y estaría integrado por los alcaldes provinciales, lo que permitiría la coordinación entre ambos niveles.

El concejo distrital tendría un alcalde y un teniente alcalde distrital elegidos directamente por la población y estaría integrado por un número de regidores determinado en proporción a la población del distrito, todos elegidos por voto directo. En el caso de distritos con gran población (como San Juan de Lurigancho, en Lima) sería deseable la aplicación del modelo de «distritos electorales», de modo que cada uno elija a un regidor. Esto permitiría una efectiva representación de los distintos sectores de la población distrital. Será necesario examinar la experiencia de alcaldes que no han contado con un cuerpo de regidores leales o de su misma agrupación para dar estabilidad al gobierno distrital.

\section{Una propuesta de regionalización pluridepartamental}

A continuación se presenta los departamentos que integrarían cada una de las regiones con sus datos de población (estimada para el año 2006) y extensión territorial:

\section{REGIÓN I}

Tumbes, Piura, Lambayeque, Cajamarca, Amazonas

Superficie: $117231,30 \mathrm{~km}^{2}$

Población: 3528000 habitantes

\section{REGIÓN II}

La Libertad, Áncash, Huánuco, Pasco y las provincias de Barranca, Cajatambo, Huaura, Huaraz y Canta del actual departamento de Lima

Superficie: $113583,15 \mathrm{~km}^{2}$, solo de los departamentos indicados

Población total (al año 2000): 4024692 habitantes

\section{REGIÓN III}

Ica, Huancavelica, Ayacucho, Apurímac y las provincias de Huarochirí, Cañete y Yauyos del departamento de Lima (colindan con Junín y Huancavelica)

Superficie: $127700,89 \mathrm{~km}^{2}$, de los departamentos

Población total (al año 2000): 2838272 habitantes

\section{REGIÓN IV}

Arequipa, Moquegua, Tacna

Superficie: 95 155,15 km²

Población: 1624000 habitantes

\section{REGIÓN V}

Junín, Cusco, Puno, Madre de Dios

Superficie: 273 483,27 km²

Población: 3963000 habitantes 


\section{REGIÓN VI}

Loreto, San Martín, Ucayali

Superficie: $522515,81 \mathrm{~km}^{2}$

Población: 2201000 habitantes

\section{REGIÓN VII: REGIÓN METROPOLITANA}

Lima Metropolitana, Provincia Constitucional del Callao

Superficie: $34948,57 \mathrm{~km}^{2}$

Población: 8270532 habitantes

(La Provincia Constitucional del Callao ha presentado siempre enorme resistencia a su integración con Lima. ¿Podría considerarse esta Región Metropolitana como capital de la República de modo que los chalacos se sintieran halagados al convertirse en parte de esta?).

\section{Otra alternativa de regionalización: por cuencas}

La propuesta de regionalización expuesta no es por cierto la única que merece ser considerada. A continuación se presenta la regionalización propuesta por el ingeniero Jaime Hoefken Peres en el documento Regionalización del Perú para su desarrollo ${ }^{1}$ :

Las siete regiones de desarrollo del Perú y Lima Metropolitana:

Región 1 o Región Norte que abarca las cuencas desde el Zarumilla hasta el Roque por la costa, y el Alto Marañón con sus cuencas Chinchipe, Chamaya,

1. Esta información se ha tomado tal como aparece en el libro de Fernando Arce Meza Hacia la reforma de la estructura organizativa del Estado peruano: historia y perspectivas. Lima, 2007, págs. 505-507.
Laucano, Cenepa, Santiago, Nieva y Utcubamba; departamentalmente comprende a Tumbes, Piura, Amazonas, norte y centro de Cajamarca y Lambayeque excepto el valle de Zaña.

Región 2 o Región Nor Centro que abarca las cuencas del Zaña, Jequetepeque hasta la del Chancay por la costa con los orígenes del Alto Marañón; departamentalmente comprende a La Libertad, Áncash, sur de Cajamarca, el valle de Zaña de Lambayeque y el norte del departamento de Lima hasta el valle de Chancay.

Región 3 o Región Sur Centro que abarca las partes altas de los ríos Chillón, Rímac y Lurín, y luego toda la cuenca del Mala hasta el Acarí por la costa, y en la parte alta, el Mantaro y el Pampas; departamentalmente comprende a Ica, Huancavelica, Ayacucho sin la naciente del río Ocoña, el valle de Pampamarca del departamento de Apurímac, los valles de Acarí y Yauca del departamento de Arequipa y el sur del departamento de Lima a partir del valle de Mala.

Región 4 o Región Sur que involucra las cuencas desde el Chala hasta el Caplina en la costa y las del Maure, Huancané, Ramis, Cabanillas, Ilpa, Ilave, Zapatilla y Callaccame en el altiplano; departamentalmente comprende a Arequipa sin los valles de Acarí y Yauca, los departamentos de Moquegua y Tacna, el centro y el sur de Puno y las nacientes del río Ocoña del departamento de Ayacucho.

Región 5 o Región Central con sus cuencas del Tambo, Perené, Ene, Pachitea y Aguaytía y sus afluentes, el Alto Huallaga con sus cuencas Mayo, Biabo, 
Sisa, Saposoa y Huallabamba; comprendería los departamentos de San Martín, Huánuco, Pasco y Junín sin el valle del Mantaro.

Región 6 o Región Sur Oriente que comprende las cuencas del Apurímac, Urubamba, Llavero, Alto Madre de Dios, Cusco, Apurímac sin el valle del Pampamarca; del departamento de Puno, el valle del Inambari; y del departamento de Ucayali, la cuenca del Alto Purús.

Región 7 o Región Nor Oriente comprende las cuencas del Bajo Ucayali, Bajo Huallaga, Bajo Marañón y Amazonas; departamentalmente comprendería los departamentos de Loreto y Ucayali sin la cuenca del Alto Purús.

\section{Región 8 o Región Administrativa de} Lima Metropolitana como una región administrativa diferente de las siete regiones que son de desarrollo. La región administrativa de Lima Metropo- litana es llamada así aunque abarca algo más, pues sus límites irían desde Ancón por el norte, Pucusana por el sur y el pueblo de Ricardo Palma por el centro.

\section{Conclusión}

Si bien ya se inició el proceso de descentralización, es imperativo perfeccionarlo. A esto contribuirá la reducción del número de regiones, de modo que las agrupaciones de los actuales departamentos permitan un efectivo desarrollo sostenible al contar con mejores bases de recursos naturales. Asimismo, habrá ahorro en los gastos burocráticos y mejoras perceptibles en la administración al crearse condiciones para una mejor coordinación dentro de una misma región pluridepartamental.

¡Hay mucho por hacer, es imperativo comenzar ya! 